\title{
Large-scale Research on Engineering Design in Secondary Classrooms: Big Learner Data Using Energy3D Computer-Aided Design
}

\author{
Dr. Senay Purzer, Purdue University, West Lafayette (College of Engineering)
}

enay Purzer is an Associate Professor in the School of Engineering Education. She is the recipient of a 2012 NSF CAREER award, which examines how engineering students approach innovation. She serves on the editorial boards of Science Education and the Journal of Pre-College Engineering Education (JPEER). She received a B.S.E with distinction in Engineering in 2009 and a B.S. degree in Physics Education in 1999. Her M.A. and Ph.D. degrees are in Science Education from Arizona State University earned in 2002 and 2008, respectively.

\section{Dr. Robin Adams, Purdue University, West Lafayette (College of Engineering)}

Robin S. Adams is an Associate Professor in the School of Engineering Education at Purdue University and holds a PhD in Education, an MS in Materials Science and Engineering, and a BS in Mechanical Engineering. She researches cross-disciplinarity ways of thinking, acting and being; design learning; and engineering education transformation.

\section{Ms. Molly H Goldstein, Purdue University, West Lafayette (College of Engineering)}

Molly Goldstein is a Ph.D. Candidate in the School of Engineering Education at Purdue University, West Lafayette with a research focus on characterizing behaviors in student designers. She previously worked as an environmental engineer specializing in air quality influencing her focus in engineering design with environmental concerns. She earned her B.S. in General Engineering (Systems Engineering \& Design) and M.S. in Systems and Entrepreneurial Engineering from the University of Illinois in UrbanaChampaign. 


\title{
NSF CORE: Large-scale Research on Engineering Design in Secondary Classrooms with Big Learner Data Using Energy3D Computer-Aided Design
}

\begin{abstract}
Through a five-year collaborative project, Purdue University and the Concord Consortium are applying a data-intensive approach to study one of the most fundamental research topics in learning sciences and engineering education: "How do secondary students learn and apply science concepts in engineering design processes?" We have collected data from over 1,000 middle and high school students in Indiana and Massachusetts through automatic, unobtrusive logging of student design processes enabled by a unique CAD tool that supports the design of energy-efficient buildings using earth science, physical science, and engineering science concepts and principles of design. Data collected includes fine-grained information of student design actions, experimentation behaviors, electronic student reflection notes, and virtual design artifacts. These process data are used to reconstruct the entire learning trajectory of each individual student. Our research evaluates how these learning analytics applied to these process data can be the computational counterparts of traditional performance assessment methods. Combining these process data with pre/post-tests and demographic data, we have investigated the common patterns of student design behavior and associated learning outcomes. We have focused on how students deepen their understanding of science concepts involved in engineering design projects and how often and deeply students use scientific experimentation to make a design choice.
\end{abstract}

\section{Key Findings}

The project started in 2014 and will continue for five years. Some key findings within the last three years of the project include investigation of common design patterns, a progression of student experimentation behaviors, and validation studies of a design conceptions instrument.

(1) Investigated common patterns of student design behaviors. ${ }^{1}$ This publication explored three protocols to measure students' engineering design solution quality, taking into account both objective and subjective design criteria. We compared high school students' design solutions and established a metric called Trade-Off Value as a way to measure artifact quality. This method of measuring measure artifact quality by focusing on how well a designer has balanced both complementary and competing design criteria provides additional information on an important design behavior and an opportunity to correlate and compare design behaviors such as balancing benefits \& tradeoffs with the representation of these behaviors in student artifacts.
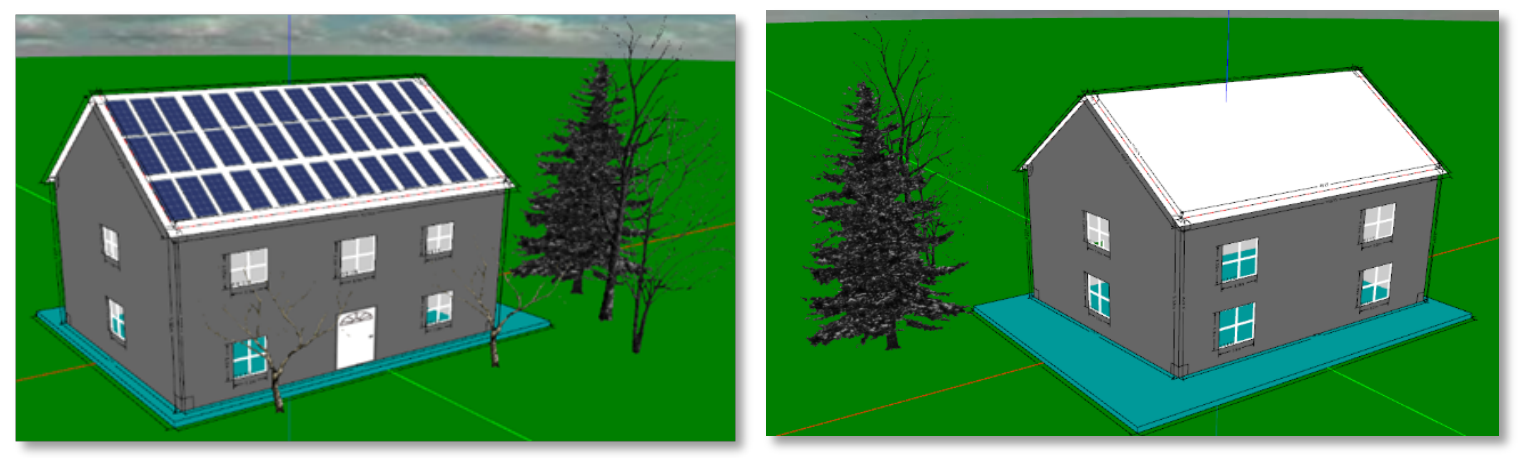

Figure 1. Design with highest Trade-off Value ${ }^{1}$ 

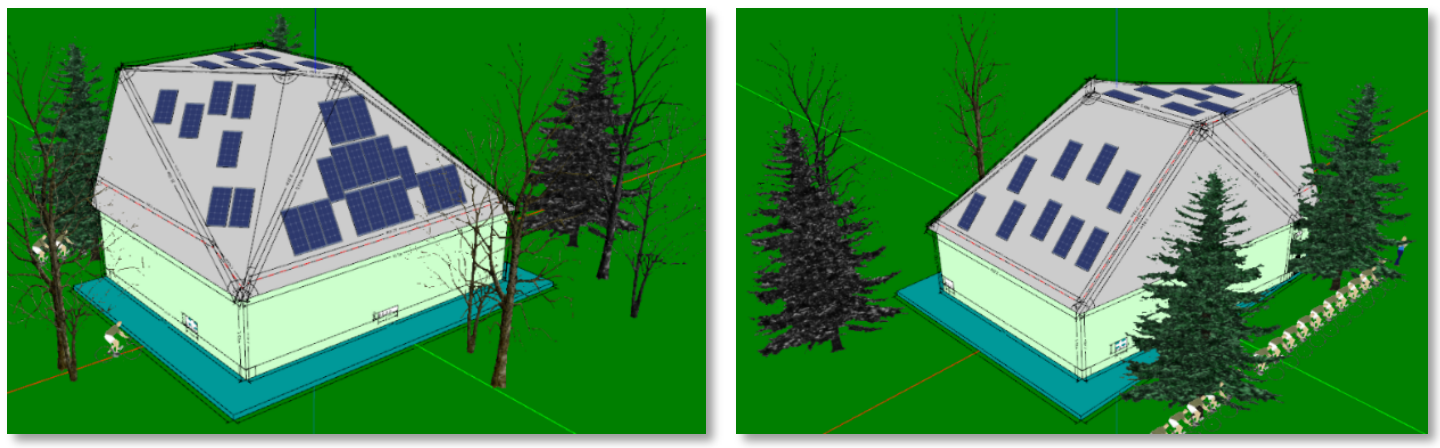

Figure 2. Design with lowest Trade-off Value ${ }^{1}$

Table 1. Comparison of design with highest and lowest Trade-off Values

\begin{tabular}{l|r|r}
\hline & Highest & Lowest \\
\hline Annual Energy Consumption $(\mathrm{kWh})$ & $-1,099$ & -17 \\
\hline Area $\left(\mathrm{m}^{2}\right)$ & 121.1 & 127.9 \\
\hline Cost $/$ vol. $\left(\$ / \mathrm{m}^{3}\right)$ & 88.74 & 114.75 \\
\hline Window-to-Wall Ratio & 0.080 & 0.009 \\
\hline \# satisfied constraints (of 8$)$ & 8 & 7 \\
\hline
\end{tabular}

(2) Applied process analytics to large datasets and evaluated efficacy of models ${ }^{2}$ Learning analytics were used to implement a model that characterizes the different strategies students use to conduct experiments. Through a two-fold study we tested the model for identifying student behaviors during design experimentation. Results suggest that the proposed model can be used to identify, characterize, and assess student strategies associated with conducting experiments.

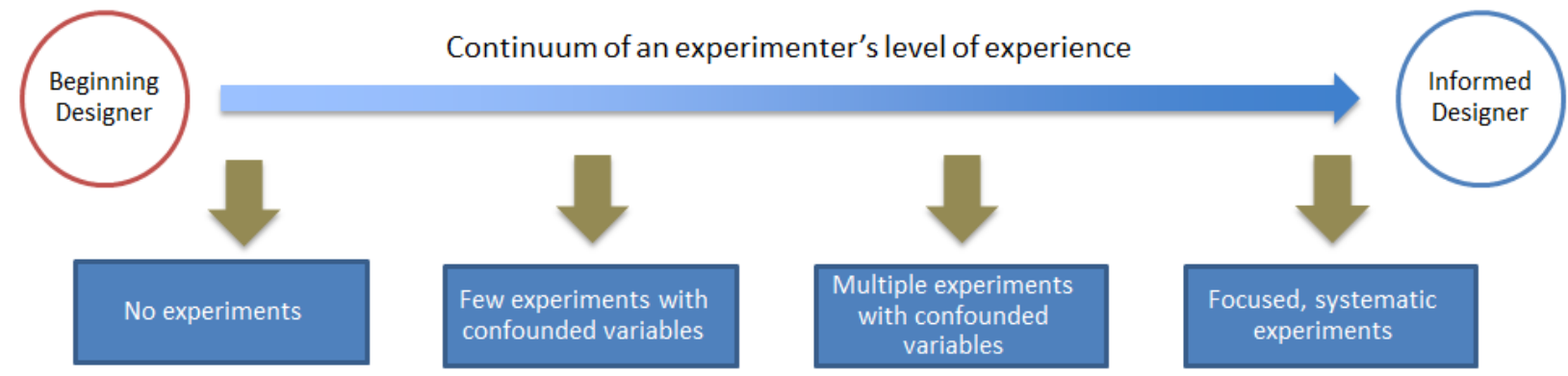

Figure 3. Experimentation strategies model ${ }^{2}$

(3) Developed and continuing to calibrate research tools and validate our research design. We are testing two research tools, a science content test and a design conceptions test. This 
research contributes to the development of an instrument used to assess students' design practices. $^{3}$

\section{Future work}

Our work for the next year includes:

(1) Conducting Validation Research on the Conceptions of Design Test (CDT). Instrument validation is an on-going, iterative process. In previous years, we have carried out small-scale classroom studies to design and refine the research instruments. As the theoretical foundation, we use Kane's argument-based approach to validation and the Informed Design Teaching and Learning Matrix by Co-PI Adams. The following questions will be investigated as part of the validation efforts.

- To what extent do students understand/interpret design terms?

- To what extent do students' score on design tests reflect their behavior from design replays?

- What are patterns of relationship between design knowledge, design behaviors and design quality as determined by a cluster analysis?

(2) Applying the process analytics to large datasets. The Purdue team will focus on establishing a theoretical base connecting macro and micro level design behaviors in Year 4. The Purdue team will work closely will the Concord team in translating these theoretical groundings and hypotheses into process analytics. Essential process data will be extracted from sequences of design snapshots. As a result, the process analytics for each student will be sifted and aggregated to a database for statistical analysis to reveal patterns and trends across student groups (e.g., by age or gender) and knowledge domains (e.g., by pre-test scores on individual science concepts).

(3) Collaborating with teachers to scale up the research to over 1000 students. We will continue to work closely with our school partners, providing teacher and student workshops when necessary. At the workshops, teachers will learn about the research purpose, the design challenges, and the supporting technology. Workshops for the students will focus on capabilities of the Energy3D software and help students get familiar with the program through small design tasks.

(4) Disseminate project results. The research findings of this project will be published in journals and presented at conferences. We will also hold teacher workshops to disseminate the implications of these findings to K-12 engineering education.

\section{Acknowledgement}

We are grateful for the students who participated in this study and for their teachers who supported data collection efforts. This work presented in this manuscript is based upon work supported by the National Science Foundation under Grant DUE \#1348547 and DUE \#1348530. Any opinions, findings, and conclusions or recommendations expressed in this paper, however, are those of the authors and do not necessarily reflect the views of the NSF. 


\section{References}

1. Goldstein, M. H., Mejia, C.V., Adams, R. S., Purzer, Ş., Zielinski, M. K. (2016). Developing a measure of quality for engineering design artifacts. Conference Proceedings: Frontiers in Education (FIE) Annual Conference, Erie, PA.

2. Vieira, C., Goldstein, M. H., Purzer, Ş., Magana, A. (2016). Using learning analytics to characterize student experimentation strategies in the context of engineering design. Journal of Learning Analytics, 3(3), 291-317.

3. Goldstein, M. H., Purzer, Ş., Adams, R. S. (2017). WIP: Assessing students' changing conceptions of design. Proceedings of the $123^{\text {rd }}$ American Society for Engineering Education Annual Conference and Exposition, Columbus, Ohio. 